\title{
Treating an intervention level 1 patient: futile or brave?
}

\author{
Solomons N, MSc, Department of Dietetics, University of the Western Cape \\ Nortje N, DPhil, Department of Psychology, University of the Free State \\ Correspondence to: Nico Nortje, e-mail: Nortjen1@ufs.ac.za \\ Keywords: futile treatment, cerebral palsy, gastro-oesophageal reflux disease, palliative care, nasogastric feeding, nasojejunal feeding
}

\begin{abstract}
An ethical dilemma describes conflicting opinions by different members of the care team. This article focuses on AJ, a five-year-old child with cerebral palsy, who was born deaf and blind as a result of having contracted rubella in utero. The case is examined against Sokol's four-quadrant analysis of ethical issues, giving a framework designed to facilitate the systematic identification and analysis of clinical ethical problems. The issue is whether the medical team should have palliated AJ, or continued with invasive therapy and feeding. The conclusion is that paediatric palliative care is often difficult, but that the dietitian has a duty to contribute his or her knowledge to benefit the patient.
\end{abstract}

(P) Peer reviewed. (Submitted: 2013-03-12. Accepted: 2013-08-31.) ๑ SAJCN

S Afr J Clin Nutr 2013;26(4):176-180

\section{Introduction}

Dietitians working in hospitals often form part of a team of different doctors and health workers. Since the scope of practice of a dietetics graduate is nutrition, as defined by the Health Professions Council of South Africa (HPCSA), this is the area on which the dietitian can advise the team. However, at times, there might be a conflict of opinion when dealing with a particular case.

We present a case in which there was a difference in opinion between the dietitian and the rest of the team. The case will be presented based on Sokol's ${ }^{1}$ four-quadrant analysis of ethical issues. It is important to note that the four-quadrant approach cannot single-handedly resolve moral dilemmas in clinical ethics. Unlike the egalitarian and/or consequentialist moral theories, it does not provide a clear account of what the right action is, neither is it directly concerned with the validity of ethical theories. Rather, it is a framework that is designed to facilitate the systematic identification and analysis of clinical ethical problems. It is an "ethical stethoscope" which increases the clinician or ethicist's ability to see what is morally relevant, while highlighting the moral dynamics of the patient's case. The judgement and justification needed to resolve specific problems, such as the scope of a prior refusal of treatment, are not included in the model. This is why the approach could be fruitfully combined with a theory such as principlism, i.e. autonomy, beneficence, nonmaleficence and justice, and balancing, i.e. determining the moral weight of competing principles and assessing which takes priority.

\section{Sokol's four-quadrant analysis for ethical dilemmas}

Ethical case analysis abounds with various methodologies, such as clinical reasoning models, to assist the team that is faced with a dilemma to approach the case in a systematical manner. Sokol proposes a four-quadrant analysis (Figure 1) to logically classify information and address the spectrum of influences (factual, as well as emotional). ${ }^{1}$

\section{Medical indications}

AJ, a five-year-old child with cerebral palsy (CP), was born deaf and blind as a result of having contracted rubella in utero. He was admitted to hospital for the fourth time within a space of four months with a lower respiratory tract infection and weight loss, which was later established to be due to severe gastro-oesophageal reflux disease (GORD). Soon after birth, he also presented with impaired renal function and investigations showed that he also had dysplastic kidneys (both of his kidneys were underdeveloped). On admission to the hospital, he was fed by means of a nasogastric tube because he was suffering from severe respiratory distress. His mother and father, who cared for him at home, reported that it took him more than 45 minutes to finish a meal, and that AJ often coughed and vomited after eating. A milk scan showed that he had severe reflux up to the clavicles, as well as delayed gastric emptying. After the milk scan, his feeding was changed to nasojejunal feeds. However, because he had multiple medical problems, and because he was not a candidate for either renal replacement therapy or a renal transplant (since both of his kidneys were underdeveloped and he was suffering from congenital rubella syndrome), he was categorised as an intervention 


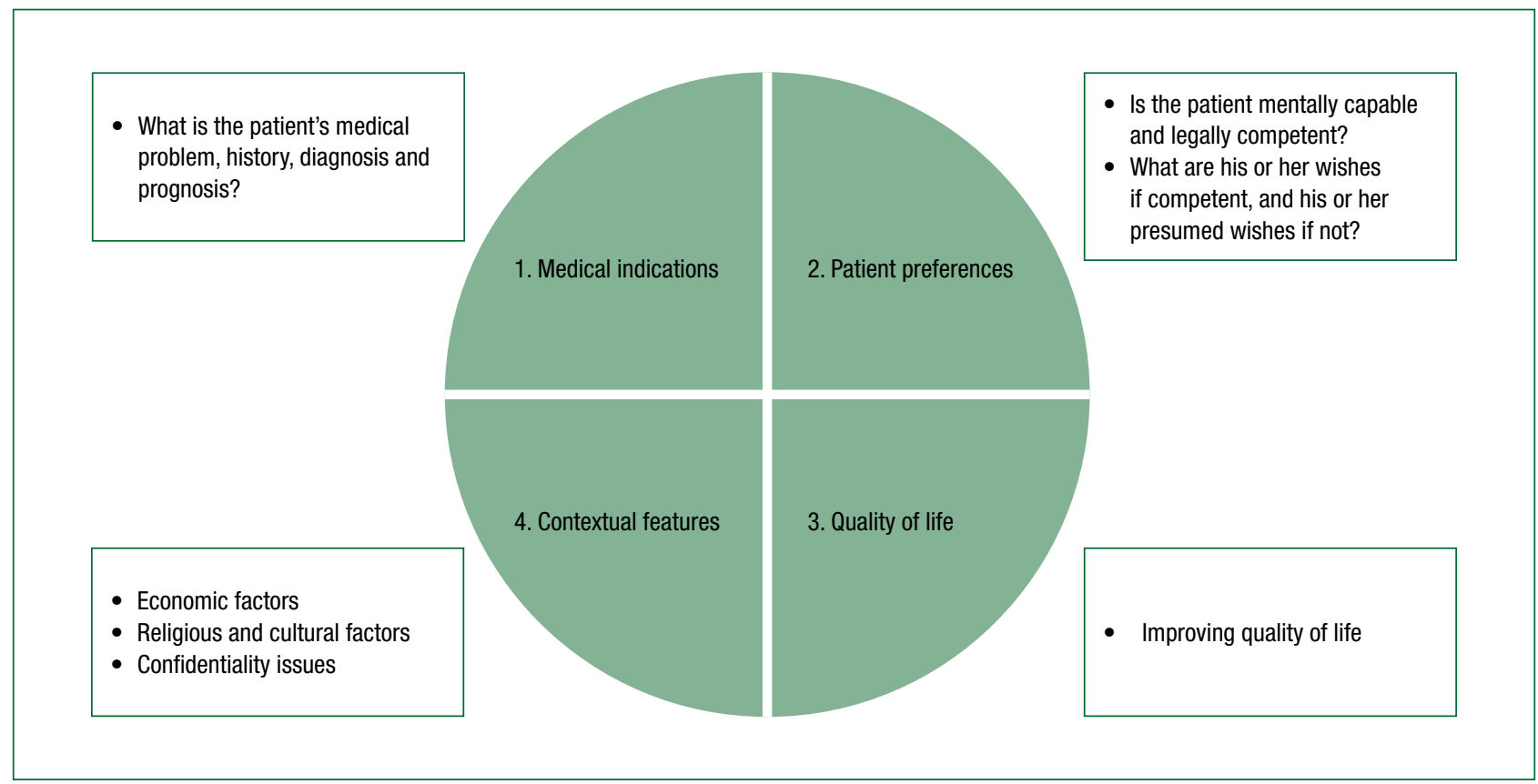

Figure 1: Four-quadrant analysis ${ }^{1}$

level 1 patient. This meant that he was not to receive any active resuscitation or intravenous antibiotics should he contract a disease, nor be given a blood transfusion should the need arise. He could only be given oral antibiotics and receive normal feeding.

Two weeks after his hospital admission, his respiratory infection cleared up, and a decision was taken to perform a Nissen fundoplication, as well as to insert a feeding gastrostomy in order for him to be discharged. A Nissen fundoplication is a surgical procedure in which the top part of the stomach (fundus) is wrapped around the lower end of the oesophagus in order to prevent the stomach contents from moving back up into the oesophagus and/or oral cavity. It can be performed in two ways: either by means of a laparoscope (a less invasive option) or open surgery (invasive). The benefits of this procedure include a reduced risk of aspiration in persons who are suffering from severe gastro-oesophageal reflux. ${ }^{2}$ Postoperative complications include gas-bloat syndrome (a combination of gagging, vomiting, nausea and abdominal distension), dysphagia and dumping syndrome, as well as the usual risks associated with surgical procedures, such as infection. ${ }^{3}$ Studies have shown that neurologically impaired and premature infant populations are at highest risk of postoperative complications. ${ }^{3}$ Because of intestinal anomalies found during the preoperative diagnostic examination, AJ underwent an open surgical placement of the gastrostomy, as well as the Nissen fundoplication procedure, after his mother had been counselled by the doctors and had signed a consent form for the procedure. Three days after the Nissen fundoplication procedure and placement of the feeding gastrostomy, AJ passed away due to complications associated with the surgery.

\section{Patient preferences}

Since this section of the analysis falls within the deontological tradition of patient autonomy and the patient was too young to consent legally to the procedures, as well as not understanding the consequences of a decision, his parents were given the responsibility of becoming his proxy (a person close to the patient who has his or her best interests at heart). In AJ's case, his mother granted permission for the operation (Nissen fundoplication and feeding gastrostomy tube placement) based on the premise that she was fully informed and had his best interests at heart.

\section{Quality of life}

\section{Cerebral palsy}

$\mathrm{CP}$ is defined as a group of permanent disorders that pertain to the development of movement and posture, causing activity limitation that is attributed to non-progressive disturbances which occur in the developing foetal or infant brain. ${ }^{4-9}$ It has been documented that CP occurs in 2-2.5/1 000 live births. ${ }^{10}$ Causes of CP include being born before term, not receiving enough oxygen during the birth, the foetus being exposed to maternal infection and/or inflammation in utero, and maternal fever during labour. ${ }^{6} \mathrm{CP}$ is classified according to movement disorder as either spastic, ataxic, dystonic or athetotic, and according to limb involvement as hemiplegic or quadriplegic. ${ }^{7}$

CP sufferers often have visual, hearing and cognitive defects and epilepsy. ${ }^{5-7,9,11}$ Other systemic defects are also present, the most common noncerebral defects being cardiac (29\%), musculoskeletal $(14 \%)$, urinary tract $(9 \%)$ and facial clefts $(9 \%) .{ }^{2,6}$

CP sufferers also often experience feeding problems because of poor hand to mouth coordination, spilling, poor lip closure and frequent regurgitation or vomiting which results in malnutrition. ${ }^{12}$ Being malnourished reduces CP-sufferers' well-being, decreases their quality of life and limits their ability to participate in their rehabilitation therapy and other activities. ${ }^{12}$ Therefore, improving a CP sufferer's nutritional status through nutritional support via tube feeding, the most common being gastrostomy feeding, aids in 
better overall health, reduces spasticity and may improve his or her immune response..$^{2,12,13}$

CP sufferers' quality of life depends on the severity of the condition. Those who suffer several co-morbidities have a reduced quality of life. Various authors report that the quality of life of CP sufferers who are tube fed is less than those not being tube fed, and that tube-fed CP sufferers have more severe defects of immobility, ${ }^{5}$ and also present with more severe neurological disability and a higher mortality rate. ${ }^{13}$

\section{Gastro-oesophageal reflux disease}

Gastro-oesophageal reflux (GOR) is defined as "the passage of gastric contents into the oesophagus". ${ }^{3}$ This is a process that occurs normally with no symptoms. ${ }^{3,14} \mathrm{GOR}$ is caused by relaxation of the lower oesophageal sphincter (LES). ${ }^{3,15}$ LES relaxation is transient in healthy persons. However, delayed gastric emptying can increase the occurrence. ${ }^{3}$ GORD is defined as "the passage of gastric contents into the oesophagus that results in worrying symptoms or complications, such as faltering growth, oesophagitis and feeding difficulties". ${ }^{3,15,16}$ GORD has been found to occur more frequently in severely physically challenged children because of decreased LES tone, the inability to be positioned upright, swallowing difficulties, abnormal sensory integration, constipation, abnormal muscle tone and skeletal abnormalities. ${ }^{3}$ Aspiration should be suspected when a chronic cough, a chronic lung infection, weight loss, poorly controlled asthma or recurrent pneumonia is experienced. ${ }^{15-18}$ If left untreated, GORD can result in complications such as a failure to thrive, dental erosion and erosive oesophagitis. ${ }^{17,19-21}$

\section{Contextual features}

AJ's mother, who had completed Grade 10, was counselled in her mother tongue (isiXhosa) about her child's condition by a panel who included the palliative care team, the doctors involved in her child's treatment, as well a social worker. It was noted that she understood her child's condition and signed a consent form agreeing that $A J$ would not be resuscitated should he fall into cardiac arrest.

Table I provides a summary of the case according to Sokol's methodology. ${ }^{1}$

Table I: Summary of the case according to Sokol's methodology ${ }^{1}$

\begin{tabular}{|l|l|}
\hline Quadrant descriptor & Summary \\
\hline Medical indications & $\begin{array}{l}\text { Child (five years of age) with cerebral palsy } \\
\text { Severe gastro-oesophageal reflux disease } \\
\text { Severe respiratory distress } \\
\text { Intestinal anomalies } \\
\text { Intervention level 1 patient classified }\end{array}$ \\
\hline Patient preference & $\begin{array}{l}\text { Not legally competent (age and cognitive ability) } \\
\text { Mother was proxy }\end{array}$ \\
\hline Quality of life & $\begin{array}{l}\text { Experienced feeding problems } \\
\text { Co-morbidities } \\
\text { Immobility } \\
\text { Gastro-oesophageal reflux disease and risk of } \\
\text { aspiration }\end{array}$ \\
\hline Contextual features & $\begin{array}{l}\text { isiXhosa culture } \\
\text { The mother was partly schooled. She understood } \\
\text { her child's condition }\end{array}$ \\
\hline
\end{tabular}

\section{Ethical dilemma}

Since a multi-professional team was involved in the care of AJ, ethical conflict arose in that some members of the team felt they had done everything they could to help AJ (rule-based ethics), as opposed to others who felt that the last treatment was futile, and that AJ would have benefited more from ethics of care (a normative feministic ethical approach that argues that those vulnerable to our choices deserve extra consideration).

Regardless of the patient's prognosis, because he had been classified as intervention level 1 , and also because the mother had been counselled and knew what to expect, the doctors continued performing invasive surgery on AJ. This raises the question as to whether the medical team should not have only made him comfortable and given him palliative care, and whether the doctors should have been allowed to conduct surgery on him.

\section{Discussion}

The issue at hand is whether the medical team should have palliated AJ or continued with invasive therapy and feeding. Table II provides a summary, proposed by the North American Society for Pediatric Gastroenterology, on alternatives to paediatric feeding.

When applying the feeding options in Table I to AJ, oral feeding was not possible since he was suffering from severe GORD, as well as delayed gastric emptying. He also reportedly took a long time to feed orally and would thus not be able to achieve an adequate nutritional intake via this route of feeding.

Nasogastric feeding was also not an option since this would exacerbate the reflux. Since the stomach contents remained in the stomach for longer (delayed gastric emptying), the chances of food refluxing back up into the oesophagus and into the lungs were increased.

Nasojejunal feeding was a good option since food is introduced into the gastrointestinal tract at a point below the stomach, where pressure was not placed on the lower oesophageal sphincter, and food was not present in the stomach, which minimises the chances of reflux.

Feeding gastrostomy is the best option for persons with long-term feeding difficulties. All surgery, even minor, is associated with complications. As AJ was classified as an intervention level 1 patient, he was at an unfair disadvantage before he entered the operating theatre. In view of the intervention level assigned to AJ, this was not the best option.

Taking all of these points and the final outcome of the case into consideration, and AJ passing away owing to complications from the surgery, it would have possibly been to his beneficence if the team had opted for a position of palliative care and inserted a nasojejunal feeding tube to alleviate pain and discomfort, and in this way, allowed him to have better quality of life towards the end.

The ethical tension inherent in all paediatric cases when the prognosis is grim is compounded by medical uncertainty. According 
Table II: Paediatric feeding options adapted from the proposals of the North American Society for Pediatric Gastroenterology ${ }^{13}$

\begin{tabular}{|c|c|c|c|c|}
\hline Feeding method & Indications & Contraindications & Advantages & Disadvantages \\
\hline Oral & $\begin{array}{l}\text { - Awake, alert, and able and } \\
\text { willing to take in food orally } \\
\text { - Gut is functioning }\end{array}$ & $\begin{array}{l}\text { - Comatose and unwilling to } \\
\text { take in food } \\
\text { - Non-functioning gut } \\
\text { - Severe gastro-oesophageal } \\
\text { reflux and delayed gastric } \\
\text { emptying (persons at risk of } \\
\text { aspiration) }\end{array}$ & Natural & None \\
\hline $\begin{array}{l}\text { Nasogastric } \\
\text { feeding }\end{array}$ & $\begin{array}{l}\text { - Unwilling or unable to take } \\
\text { in enough food to meet } \\
\text { nutritional requirements } \\
\text { - Functioning gut }\end{array}$ & $\begin{array}{l}\text { - Non-functioning gut } \\
\text { - Delayed gastric emptying } \\
\text { - Severe gastro-oesophageal } \\
\text { reflux }\end{array}$ & $\begin{array}{l}\text { - It stimulates physiological, } \\
\text { digestive and hormonal } \\
\text { responses } \\
\text { - Allows for a more flexible } \\
\text { feeding schedule } \\
\text { - The feeding tube is easy to } \\
\text { place } \\
\text { - Feeds can be administered as } \\
\text { either a bolus or continuously } \\
\text { - When administered as a bolus } \\
\text { feed, the use of a feeding } \\
\text { pump is not required }\end{array}$ & $\begin{array}{l}\text { - Nasal irritation. } \\
\text { - Not for long-term feeding } \\
\text { - Easily dislodged } \\
\text { - Tube can migrate } \\
\text { - If administered continuously, a } \\
\text { feeding pump is needed }\end{array}$ \\
\hline $\begin{array}{l}\text { Nasojejunal } \\
\text { feeding }\end{array}$ & Severe gastro-oesophageal reflux & Non-functioning gut & $\begin{array}{l}\text { Minimises the possibility of } \\
\text { aspiration }\end{array}$ & $\begin{array}{l}\text { - Not for long-term feeding } \\
\text { - Requires a feeding pump } \\
\text { - Can easily migrate into the } \\
\text { stomach } \\
\text { - Is difficult to place } \\
\text { - Position needs to be } \\
\text { confirmed by means of an } \\
\text { X-ray }\end{array}$ \\
\hline $\begin{array}{l}\text { Feeding } \\
\text { gastrostomy }\end{array}$ & $\begin{array}{l}\text { - Severe gastro-oesophageal } \\
\text { reflux (when placed in } \\
\text { conjunction with a Nissen } \\
\text { fundoplication) } \\
\text { - Incoordinate or difficulty in } \\
\text { swallowing } \\
\text { - Long-term nutrition support } \\
\text { is needed }\end{array}$ & $\begin{array}{l}\text { - Short-term nutrition support } \\
\text { - Normal swallowing }\end{array}$ & $\begin{array}{l}\text { - Feed is administered as a } \\
\text { bolus, allowing for a flexible } \\
\text { feeding schedule } \\
\text { - For long-term use }\end{array}$ & $\begin{array}{l}\text { - Infections } \\
\text { - Tissue granulation } \\
\text { - Tube can come out }\end{array}$ \\
\hline
\end{tabular}

to Rhoden, ${ }^{22}$ Swedish doctors tend to withhold treatment from the beginning if the statistical data show a low rate of success. The trend in the USA is that doctors will treat those who are potentially viable and will continue to do so until it is virtually certain that the child will die. ${ }^{22,23}$ In the UK, the tendency is that doctors are more likely to initiate treatment, but to withdraw it if appears likely that the infant will not survive. No corresponding data are available for South Africa.

However, guidelines from the HPCSA ${ }^{24}$ are very pertinent in that they state that:

- A healthcare institution is obliged to provide the appropriate palliative care and follow-up when specialised care is withheld.

- Whatever decision is made, healthcare practitioners must ensure that everybody consulted, and especially those responsible for delivering care, are informed of the decision and are clear about the goals and the agreed management plan.

The plight of the original Bloomington Baby Doe, who suffered from Down's syndrome and an oesophageal defect, and whose water and feeding was withdrawn and medical treatment withheld, has come to exemplify the nature of these dilemmas for many. All Baby Doe dilemmas involve the vexing ethical questions of whether or not quality-of-life judgements are justifiable, and if so, how they can be appropriately circumscribed. But medical uncertainty compounds these dilemmas enormously. In these cases, doctors do not know whether or not the baby will live, and if it does survive, they cannot predict what degree of handicap, if any, he or she may have. This medical uncertainty creates another level of ethical uncertainty: how to make life or death decisions for infants in the absence of the necessary information required to predict or evaluate their future quality of life..$^{22,23}$

When a child has a life-threatening condition, parents and clinicians often struggle to promote his or her well-being, minimise the pain and suffering, and make way for a humane death. Decisions involve deeply held values about life, death and disability, and ethical conflicts can arise. The emotions surrounding end-of-life care can magnify such conflict. Decisions made at this time will have lasting consequences for the child, the family and the clinicians..$^{25}$

Because of AJ's multiple medical problems, the palliative team designated AJ as an intervention 1 level patient. However, despite this, a decision was made to perform anti-reflux surgery and to place a feeding gastrostomy tube. In a country with limited resources, and when viewed in accordance with the utilitarian tradition to which our healthcare system subscribes (benefit to the greater number), 
the action taken was not in the best interest of the patient. Because of intestinal anomalies found during the preoperative workup, AJ should have only had to undergo an open Nissen fundoplication procedure and placement of the feeding gastrostomy.

Do we owe a duty of care to young vulnerable children in the same position as AJ, or do we need to do everything in our power to save the child, regardless of the outcome?

\section{References}

1. Sokol DK. The "four quadrants" approach to clinical ethics case analysis; an application and review. J Med Ethics. 2008;34(7):513-516.

2. Kane TD. Laparoscopic Nissen fundoplication. Minerva Chir. 2009;64(2):147-157.

3. Sullivan JS, Sundaram SS. Gastroesophageal reflux. Paediatr Rev. 2012;33(6):243-254.

4. Krigger KW. Cerebral palsy: an overview. Am Fam Physician. 2006;73(1):91-100.

5. Livingston MH, Rosenbaum PL, Russell DJ, Palisano RJ. Quality of life among adolescents with cerebral palsy: what does the literature say? Dev Med Child Neurol. 2007;49(3):225-231.

6. Moreno-De-Luca A, Ledbetter D, Martin C. Genetic insights into the causes and classification of the cerebral palsies. Lancet Neurol. 2012;11(3):283-292.

7. 0'Shea M. Cerebral palsy. Semin Perinatol. 2008;32(1):35-41.

8. Rankin J, Cans C, Garne E, et al. Congenital anomalies in children with cerebtral palsy: a population-based record linkage study. Dev Med Child Neurol. 2010;52(4):345-351.

9. Zarrinkalam R, Russo RN, Gibson CS, et al. CP or Not CP? A review of diagnoses in a cerebral palsy register. Pediatr Neurol. 2010;42(3):177-180.

10. Best JM. Rubella. Semin Fetal Neonatal Med. 2007;12(3):182-192.

11. Andrew MJ, Sullivan PB. Feeding difficulties in disabled children. Paediatr Child Health 2010;20(7):321-326.
12. Marchand V. A practical approach to nutrition care in neurologically impaired children Clinical Nutrition Highlights. 2012;8(2):2-9.

13. Marchand V, Motil KJ, NASPGHAN Committee on Nutrition. Nutrition support for neurologically impaired children: a clinical report of the North American Society for Pediatric Gastroenterology, Hepatology and Nutrition. J Pediatr Gastroenterol Nutr. 2006;43:123-135.

14. Kumar P, Clark M, editors. Clinical medicine. $6^{\text {th }}$ ed. London: Elsevier Saunders; 2005.

15. Carroll MW, Jacobsen K. Gastroesophageal reflux disease in children and adolescents: when and how to treat. Paediatr Drugs. 2012;14(2):79-89.

16. Shaw V, Lawson M. Clinical paediatric dietetics. $3^{\text {rd }}$ ed. USA: Blackwell Publishing; 2007.

17. Beckung E, White-Koning M, Marcelli M, et al. Health status of children with cerebral palsy living in Europe: a multi-centre study. Child Care Health Dev. 2008;34(6): 806-814.

18. Hassall E. Step-up and step-down approaches to treatment of gastroesophageal reflux disease in children. Curr Gastroenterol Rep. 2008;10(3):324-331

19. Ruigómez A, Wallander M, Lundborg $P$, et al. Gastroesophageal reflux disease in children and adolescents in primary care. Scand J Gastroenterol. 2010;45(2):139-146.

20. Kane TD, Brown MF, Chen MK, Members of the APSA New Technology Committee. Position paper on laparoscopic antireflux oprations in infants and children for gastroesophageal reflux disease. American Pediatric Surgery Association. J Pediatr Surg. 2009:44(4):1034-1040

21. Van Niekerk ML, Visser A, Venter DJ. Laparoscopic antireflux surgery in infants and children. S Afr Med J. 2005;95(9):676-678.

22. Rhoden NK. Treating Baby Doe: the ethics of uncertainty. Hastings Cent Rep. 1986;16(4):34-42.

23. Leira EC, Ludwig BR, Gurol ME, et al. The types of neurological deficits might not justify withholding treatment in patients with low total National Institutes of Health Stroke Scale scores. Stroke. 2012;43(3):782-786.

24. Health Professions Council of South Africa. Guidelines for the withholding and withdrawing of treatment. $2^{\text {nd }}$ ed. HPCSA: Pretoria; 2007.

25. Rushton CH. Ethics and palliative care in paediatrics. Am J Nurs. 2004;104(4): 54-64. 